\title{
New Immunotherapeutic Approaches for Glioblastoma
}

\author{
Gustavo Ignacio Vázquez Cervantes $\mathbb{B D}^{1,2}$ Dinora F. González Esquivel $\mathbb{B}^{\mathbb{D}}{ }^{1}$ \\ Saúl Gómez-Manzo $\mathbb{D}^{3}{ }^{3}$ Benjamín Pineda $\mathbb{D}^{4},{ }^{4}$ and Verónica Pérez de la Cruz $\mathbb{D}^{1}$ \\ ${ }^{1}$ Neurochemistry and Behavior Laboratory, National Institute of Neurology and Neurosurgery "Manuel Velasco Suárez", \\ Mexico City 14269, Mexico \\ ${ }^{2}$ Posgrado en Ciencias Biológicas, Unidad de Posgrado, Edificio A, $1^{\circ}$ Piso, Circuito de Posgrados, Ciudad Universitaria, Coyoacán, \\ C.P. 04510 Distrito Federal, Mexico \\ ${ }^{3}$ Laboratorio de Bioquímica Genética, Instituto Nacional de Pediatría, Secretaría de Salud, México City 04530, Mexico \\ ${ }^{4}$ Neuroimmunology Department, National Institute of Neurology and Neurosurgery "Manuel Velasco Suárez", \\ Mexico City 14269, Mexico
}

Correspondence should be addressed to Benjamín Pineda; benpio76@hotmail.com and Verónica Pérez de la Cruz; veped@yahoo.com.mx

Received 22 June 2021; Accepted 24 August 2021; Published 14 September 2021

Academic Editor: Xiao-Jie Lu

Copyright (c) 2021 Gustavo Ignacio Vázquez Cervantes et al. This is an open access article distributed under the Creative Commons Attribution License, which permits unrestricted use, distribution, and reproduction in any medium, provided the original work is properly cited.

\begin{abstract}
Glioblastoma (GBM) is the most common primary malignant brain tumor with a high mortality rate. The current treatment consists of surgical resection, radiation, and chemotherapy; however, the median survival rate is only 12-18 months despite these alternatives, highlighting the urgent need to find new strategies. The heterogeneity of GBM makes this tumor difficult to treat, and the immunotherapies result in an attractive approach to modulate the antitumoral immune responses favoring the tumor eradication. The immunotherapies for GMB including monoclonal antibodies, checkpoint inhibitors, vaccines, and oncolytic viruses, among others, have shown favorable results alone or as a multimodal treatment. In this review, we summarize and discuss promising immunotherapies for GBM currently under preclinical investigation as well as in clinical trials.
\end{abstract}

\section{Introduction}

Glioblastoma multiforme (GBM) stands as the most frequent and aggressive form of the central nervous system (CNS) primary neoplasms. The standard protocol for treating this malignancy recommends, if possible, maximal surgical resection of the tumor mass followed by radiotherapy with adjuvant and concomitant temozolomide or a combination of procarbazine, lomustine, and vincristine (PCV schedule) for recurrent glioblastoma [1]. However, the standard of care (SOC) protocols have only prolonged from 10-12 months to 14-16 months the median of overall survival (OS) of GBM patients and only 5-year survival in $5 \%$; thus, GBM remains an incurable disease [2].

During the early tumor formation, immune surveillance allows carrying out antitumor immune responses mediated by M1 macrophages, natural killer cells (NKs), and antigenspecific lymphocytes. However, GBM cells become able to elicit a series of mechanisms that permit the recruitment of monocytes that become tumor-associated macrophages (TAMs) as well as the recruitment of tumor tolerogenic lymphocytes like $\mathrm{T}$ regulatory cells (Tregs) with the production of antiinflammatory cytokines such as TGF- $\beta$, VEFG, and interleukin- (IL-) 6 and 10 [3, 4], besides the expression of immune checkpoint molecules that inhibit cytotoxic immune response, cytotoxic T lymphocyte antigen-4 (CTLA-4), and programmed cell death-1 (PD-1) $[5,6]$. These mechanisms contribute to the modelling of GBM microenvironment constituted of highly infiltrated TAMs and Tregs and the presence of anergic infiltrated cytotoxic lymphocytes, thus representing a barrier to the GBM treatment because of the maintenance of conditions favorable for tumor growth and immune escape $[7,8]$. 
Considering the immunosuppressive tumor environment, new therapies are emerging focused on reactivating the immune response against tumors as promising tools for the increase in tumor clearance and the improving patient survival. Immunotherapeutic strategies encompass the use of different substances to stimulate the antitumor immune response or the elimination of immunosuppressive cells, as well as the use of substances produced by immune components to combat tumor proliferation and immune evasion. Immunotherapeutic approaches involve the passively mediated administration of monoclonal antibodies, the use of adjuvants and cytokines, or the active-mediated immunization by antigen vaccination or transplantation of activated dendritic cells or trained cytotoxic lymphocytes, exploiting the humoral and cellular components of the immune system to directly inhibit tumor growth and abrogate the tumor-mediated immune suppressive mechanisms or to activate the innate/adaptive immune response against the tumor [9]. Some of these have been successful in treating other neoplasms such as melanoma and leukemia. Here, we summarize the most recent reports of immunotherapeutic efforts against GBM.

\section{Current Immunotherapy for Glioblastoma}

Today, the development of immunotherapeutic tools to combat GBM has begun to be tested in clinical trials. Until mid-2021, 1,646 clinical trials for GBM had been registered in the clinical trial database of the United States National Institutes of Health, of which $22.53 \%$ use one or more immunotherapeutic strategies alone or in combination with SOC (Figure 1(a)).

Within immunotherapeutic strategies, monoclonal antibodies are the most frequently used agents in GBM patients (24.45\% of the clinical trials; Figure 1(b)). These immunoglobulins are targeted to disrupt tumor homeostasis by promoting the activation of antitumor cytotoxic lymphocytes and inhibition of Tregs (Figure 1(c)). However, in light of the definition of immunotherapy, antibodies that block angiogenic signalling or those targeting the inhibition of growth factor receptors are not strictly considered immunotherapies due to the lack of evidence pointing to an immunogenic role of these antibodies. Among these, bevacizumab, a humanized antibody targeted against VEGF-A, is the most frequently used antibody for GBM therapy; the effectivity of bevacizumab in GBM patients has been summarized in recent reviews $[10,11]$, while other monoclonal antibodies tested in GBM patients are targeted against the variant III of the epidermal growth factor receptor (EGFRvIII), the vascular endothelial growth factor receptor (VEGFR), the Hepatocyte Growth Factor Receptor (HGFR), and other receptors overexpressed on GBM malignant cells [12-25]. Furthermore, the development of bispecific antibodies with multiple targets also has been tested in GBM clinical trials.

The transplant of autologous immune cells is another strategy tested in GBM patients. This requires the previous leukapheresis of the patient blood and then separation and culturing of dendritic cells, T lymphocytes, or NK cells.
These cells are stimulated and expanded in vitro and then transplanted back to their recipient [26]. Another variant consists of the use of autologous dendritic cells or T lymphocytes genetically transformed in vitro which has also recently been tested in GBM clinical trials.

The use of peptide vaccines based on malignant cell lysates or specific tumor antigens that allow the activation of antitumor immune responses represents $8 \%$ of the clinical trial tested for GBM. In some of these trials, peptide vaccination is accompanied by adjuvants that promote innate immunity; however, adjuvants have also been tried as the only immunotherapeutic resource together with SOC.

$\mathrm{T}$ cells armed with chimeric antigen receptors (CAR-Ts) possess an engineered surface receptor that combines the antigen-binding region of an antibody with the intracellular activation domains of $\mathrm{T}$ cell receptors thereby killing tumor cells by recognizing unique malignant cell surface antigens (neoantigens) [27]. CAR-Ts have evolved into a wide spectrum of molecules that have been tested against GBM. Another immunotherapeutic approach involves immunotoxins, which are engineered proteins that contain the antigenbinding regions of an immunoglobulin fused to cytotoxic molecules. The antigen-binding regions of these immunotoxins recognize tumor epitopes and selectively deliver the toxic molecules [28]. Similarly, there is the development of tumor-specific bacteria or liposomes that deliver DNA plasmids that encode proteins that interfere with tumor proliferation or encode a lymphocyte-target surface protein [29].

Oncolytic viruses are also an immunotherapeutic approach, which selectively infect malignant cells that promote cell lysis; furthermore, viral particles could activate innate immune response contributing to antitumor activity [30]. Also, recombinant cytokines such as IL-2, IL-4, IL-17, or interferon (IFN-) $\alpha$, IFN- $\beta$, or IFN- $\gamma$ have been used in GBM clinical trials. These cytokines allow the proliferation and activation of lymphocyte antitumor responses.

All these immunotherapeutic approaches are being tested in clinical trials and will be explained in detail in the next sections. Additionally, Table 1 summarizes the most relevant immunotherapies on GBM.

2.1. Monoclonal Antibodies for GBM Therapy. Monoclonal antibodies tested in GBM patients are targeted to block the mechanisms elicited by malignant cells that suppress antitumor immune responses (Figure 2(a)). The immune checkpoint molecules, CTLA-4 and PD-1, are cell surface proteins that negatively regulate the activation of $\mathrm{T}$ cells at different stages of an immune response [31]. CTLA-4 is a ligand for the costimulatory molecules $\mathrm{B} 7-1 / \mathrm{B} 7-2$ or CD80/CD86 expressed in the cell surface of activated T lymphocytes; thus, it is a competitive inhibitor of CD28, an important costimulatory receptor for the activation of $\mathrm{T}$ lymphocytes [32]. The blockade of CTLA-4 allows the binding of CD80/86 with CD28 molecules expressed on the surface of T cells, activating the costimulatory signal elicited by $\mathrm{PI} 3 \mathrm{~K}$ and AKT kinases thus promoting $\mathrm{T}$ cell activation and proliferation $[33,34]$. Furthermore, preclinical models using CTLA-4 blockade have shown to reduce the number of tumor-infiltrating Tregs, which could potentiate the 


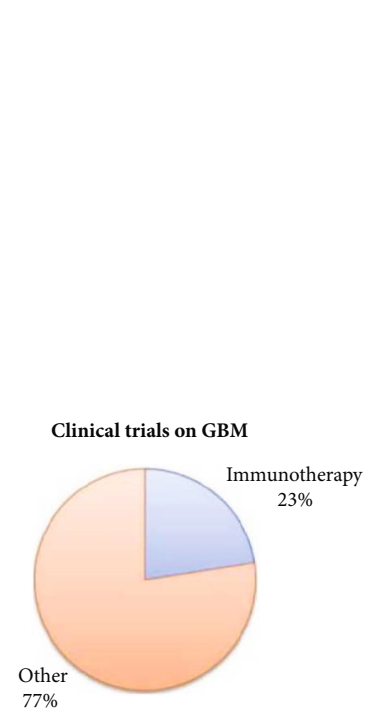

(a)

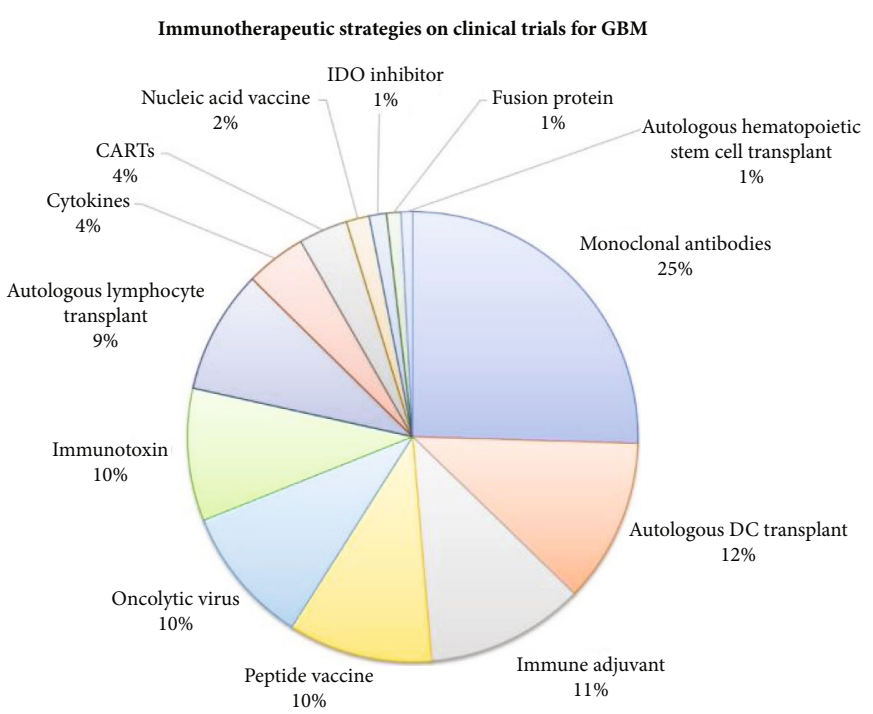

(b)

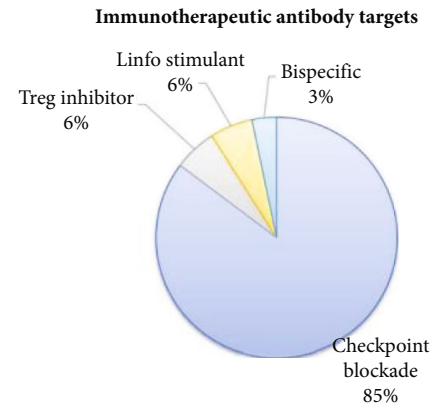

(c)

FIgURE 1: Targets of clinical trials for GBM.

antitumor response [35]. In the case of PD-1, this is a molecule expressed in mature lymphocytes; PD-1 ligation drives the blockade of activation cascades in $\mathrm{T}$ lymphocytes by interacting with the PD-1 ligands (PD-L1/2) that are constitutively expressed in professional antigen-presenting cells (APCs) and in a wide variety of cells in the organism [36]. Furthermore, PD-L1/2 is expressed in several tumors including GBM, where it acts as an immunosuppressive mechanism [31]; the use of antibodies against PD-1 or PD-L1/2 prevents the binding between these molecules thus avoiding phosphatase activity associated with PD-1 and allowing the TCR/CD3-mediated reactivation of exhausted $\mathrm{T}$ cells within the tumor [34, 37]. The development of humanized monoclonal antibodies directed against the immune checkpoint molecules, ipilimumab for CTLA-4 and nivolumab or pembrolizumab for PD-1, has shown remarkable results on OS in melanoma, lung cancer, and renal carcinoma and currently is approved for the treatment of these neoplasms [38-40]. The successful use of the immune checkpoint antibodies against melanoma brain metastasis has opened the door for the use of these agents in the treatment of GBM and its evaluation in clinical trials [41].

The combination of ipilimumab with nivolumab in untreated GBM patients has been tested in clinical trials showing partial responses accompanied by increased immune infiltrates in tumor tissue, but there was no improvement in the progression-free survival (PFS) or OS [42]. When nivolumab or ipilimumab has been used as neoadjuvant drugs, they showed that alone they had no clinical efficacy, but when they were administered before and after surgical resection, they prevented the loss of innate and adaptive immune populations induced by radiation on primary GBM [43]. Patients with recurrent GBM refractory to bevacizumab have shown greater PFS when they are treated with nivolumab [44, 45]. Besides nivolumab, pembrolizumab, the other anti-PD-1 antibody, there have been also tested patients with recurrent GBM. GMB patients who received neoadjuvant pembrolizumab with continuous adjuvant therapy after surgery showed increased CD8+ cytotoxic lymphocytes, low PD-1 levels, and then better OS and PFS results compared to GBM patients who received adjuvant, postsurgical PD-1 blockade alone [46]. Additionally, pembrolizumab has also shown prolonged PFS and OS rates after surgery on recurrent GBM patients. In this clinical trial, a slight increase in granzyme B levels was observed and no differences were found in the number of infiltrating CD4+, $\mathrm{CD} 8+$, or NK populations. However, a high infiltration of M0- or M2-type macrophages was described, explaining the poor antitumor immune response induced by treatment with pembrolizumab [47]. Separately, the responsiveness to 


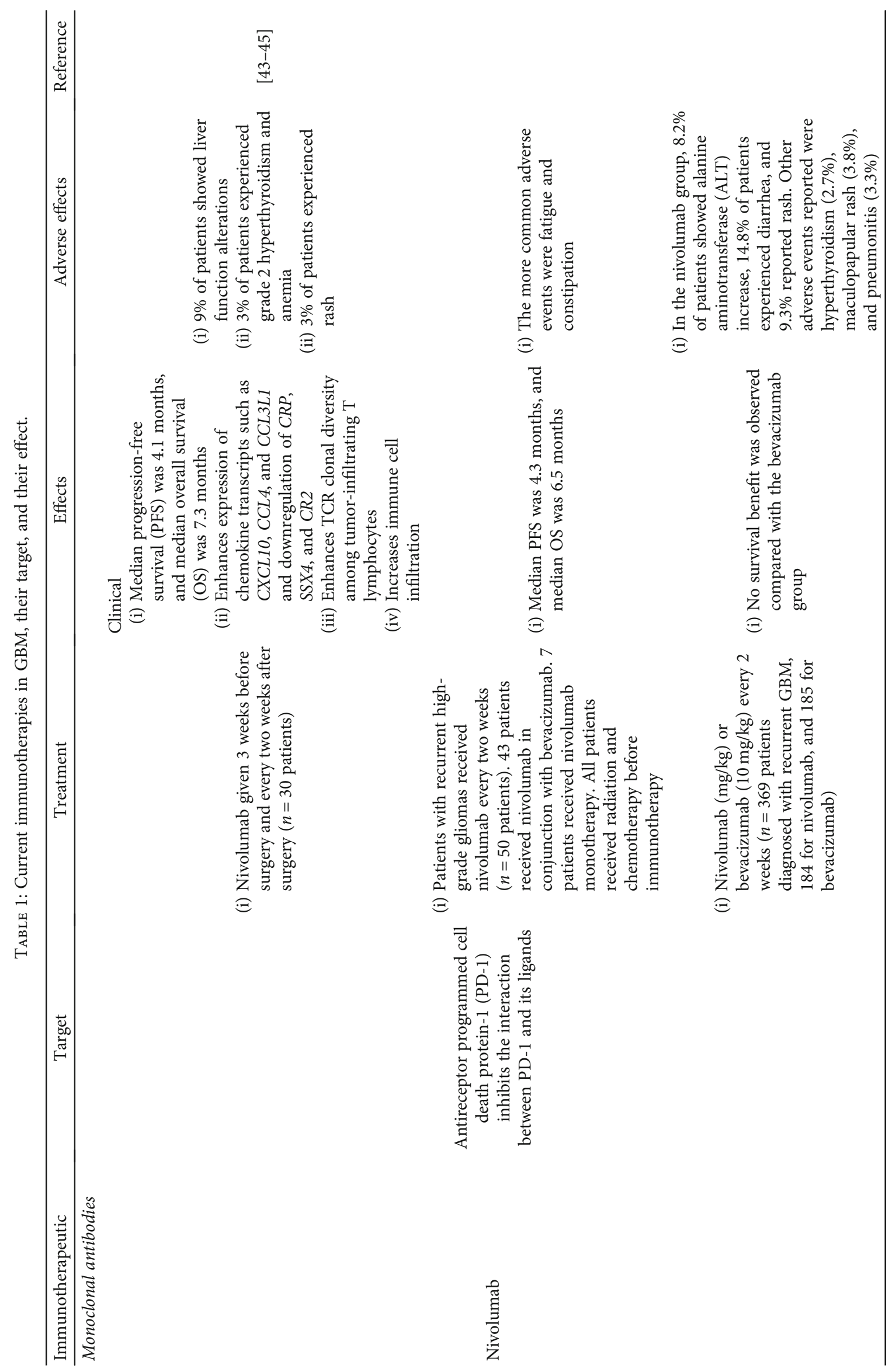




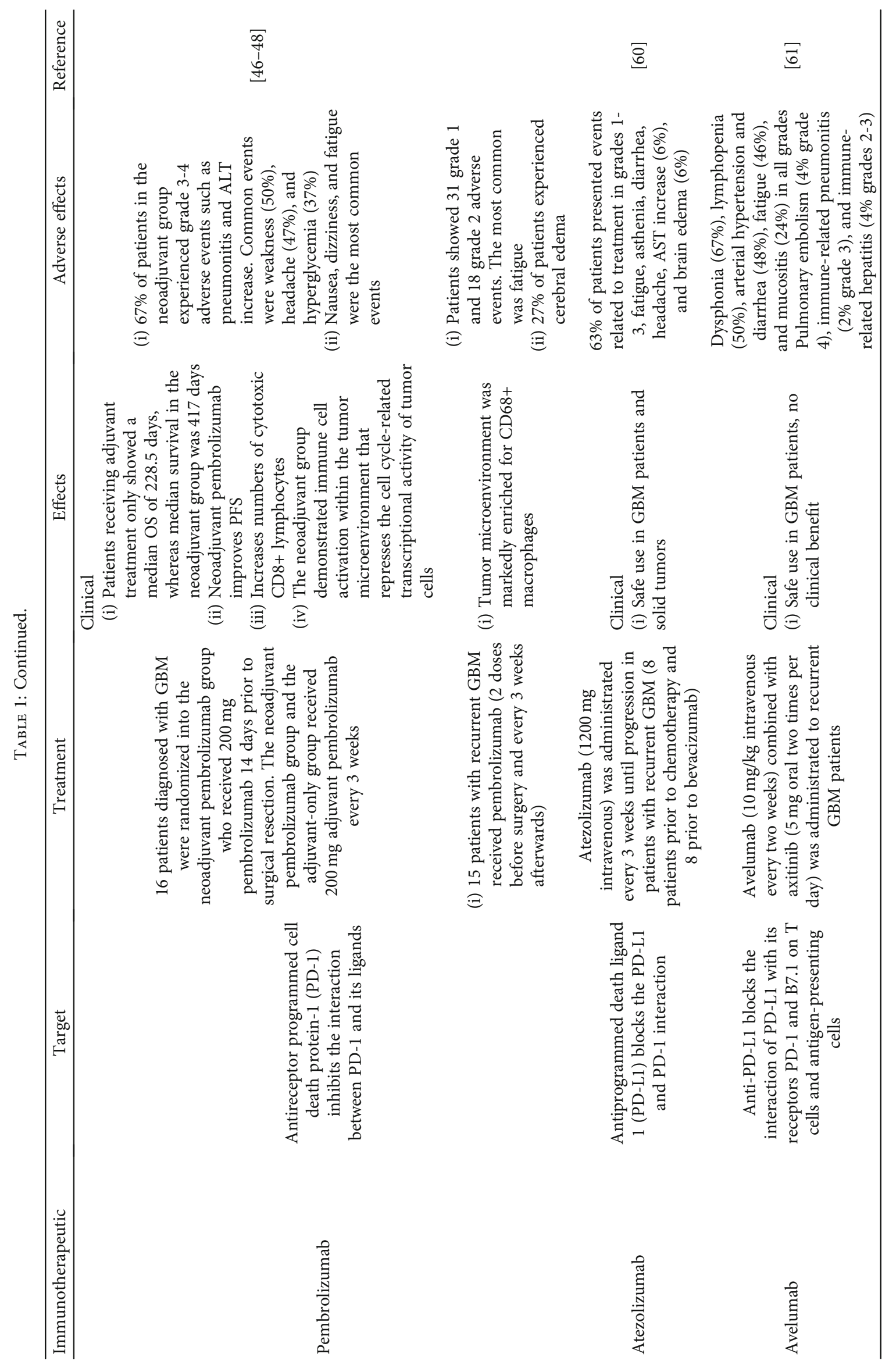




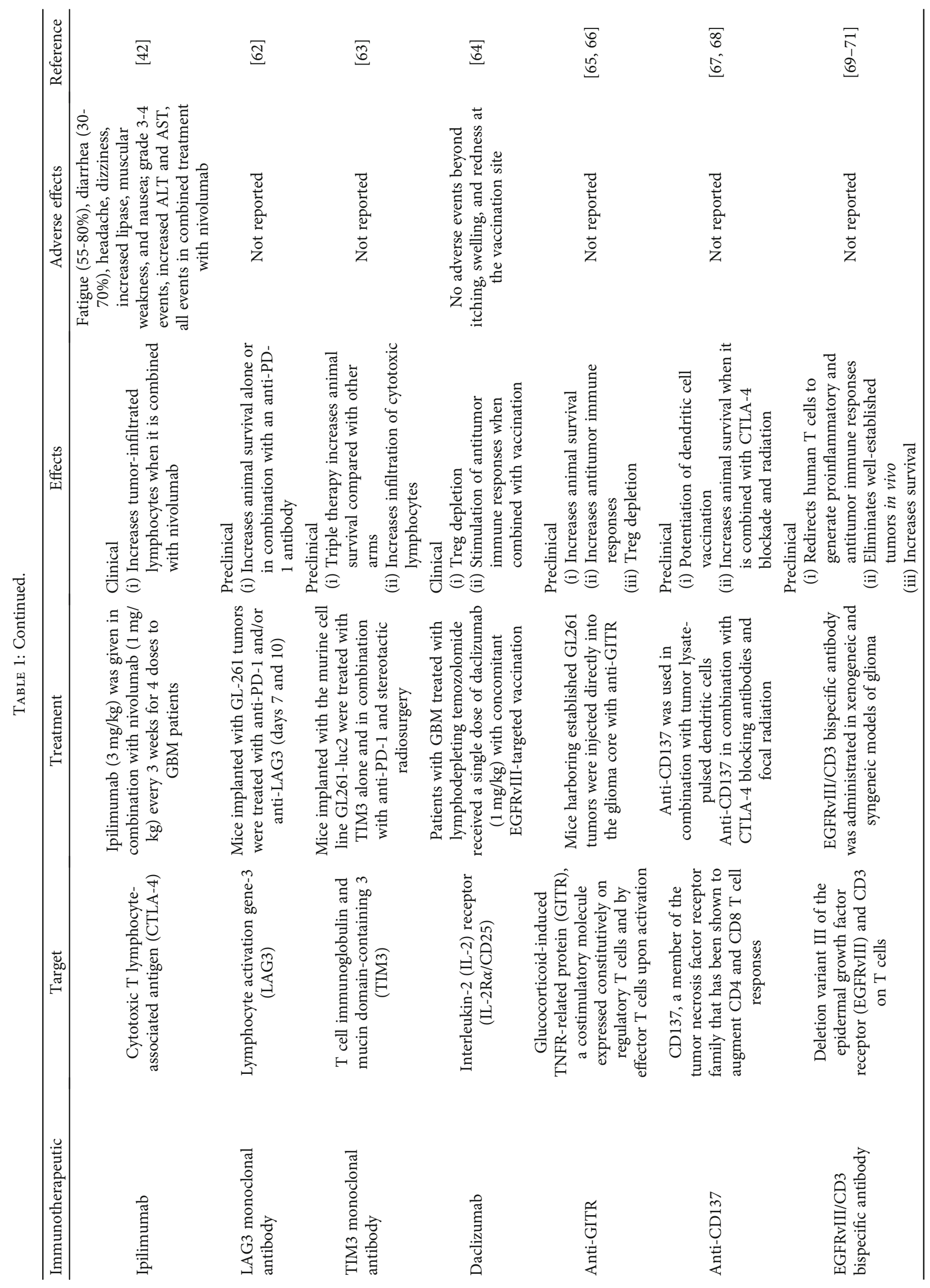




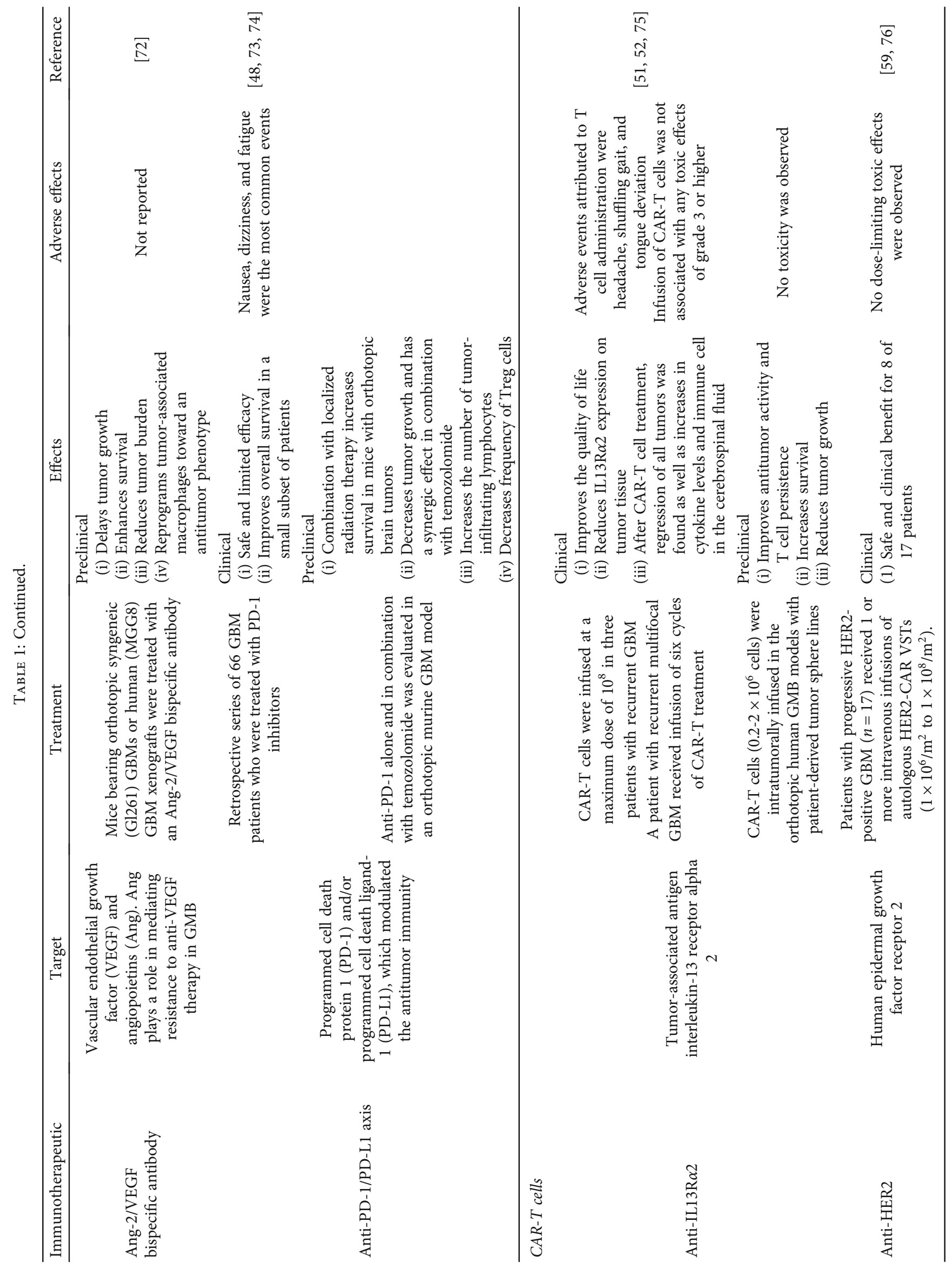




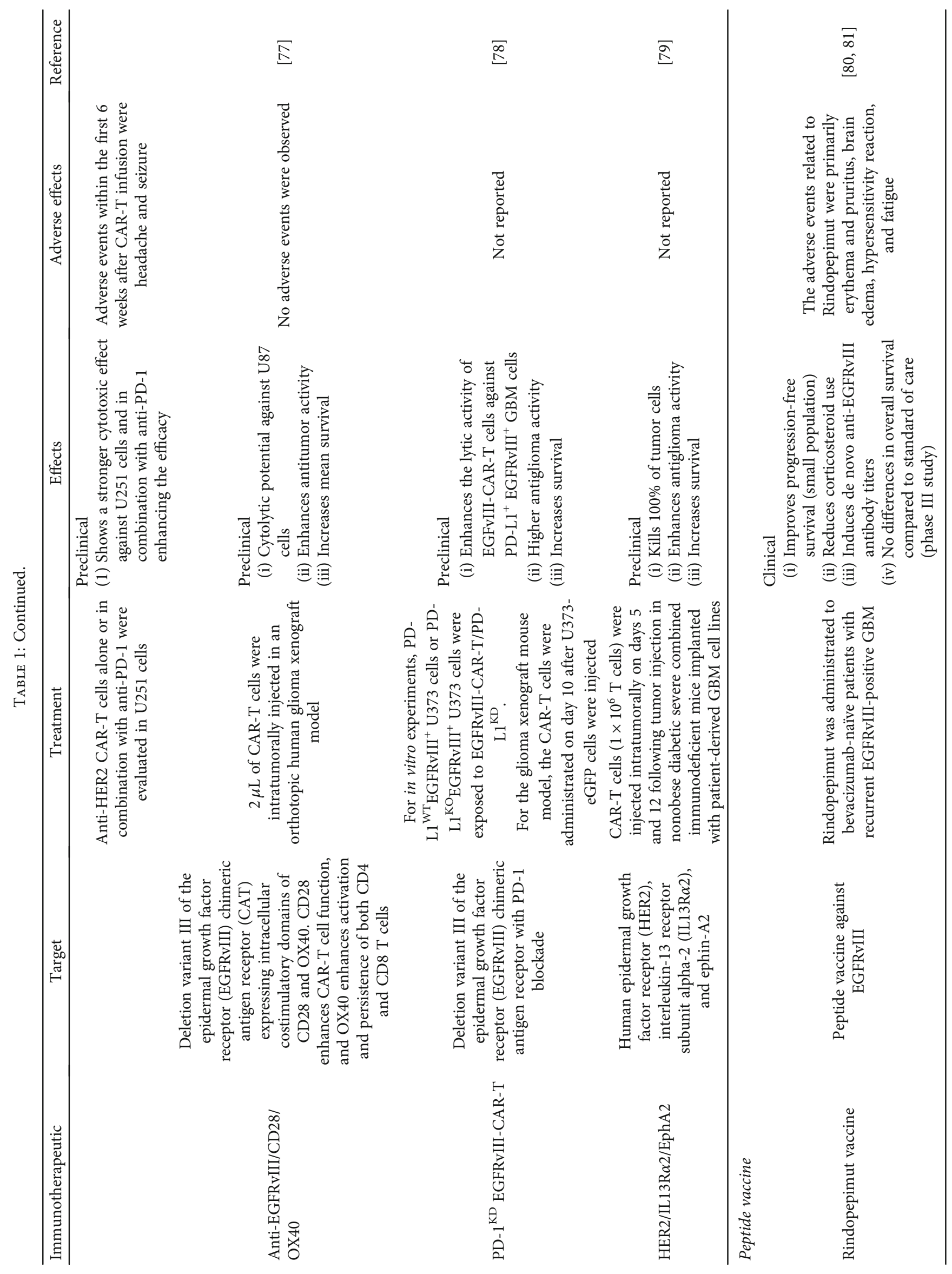




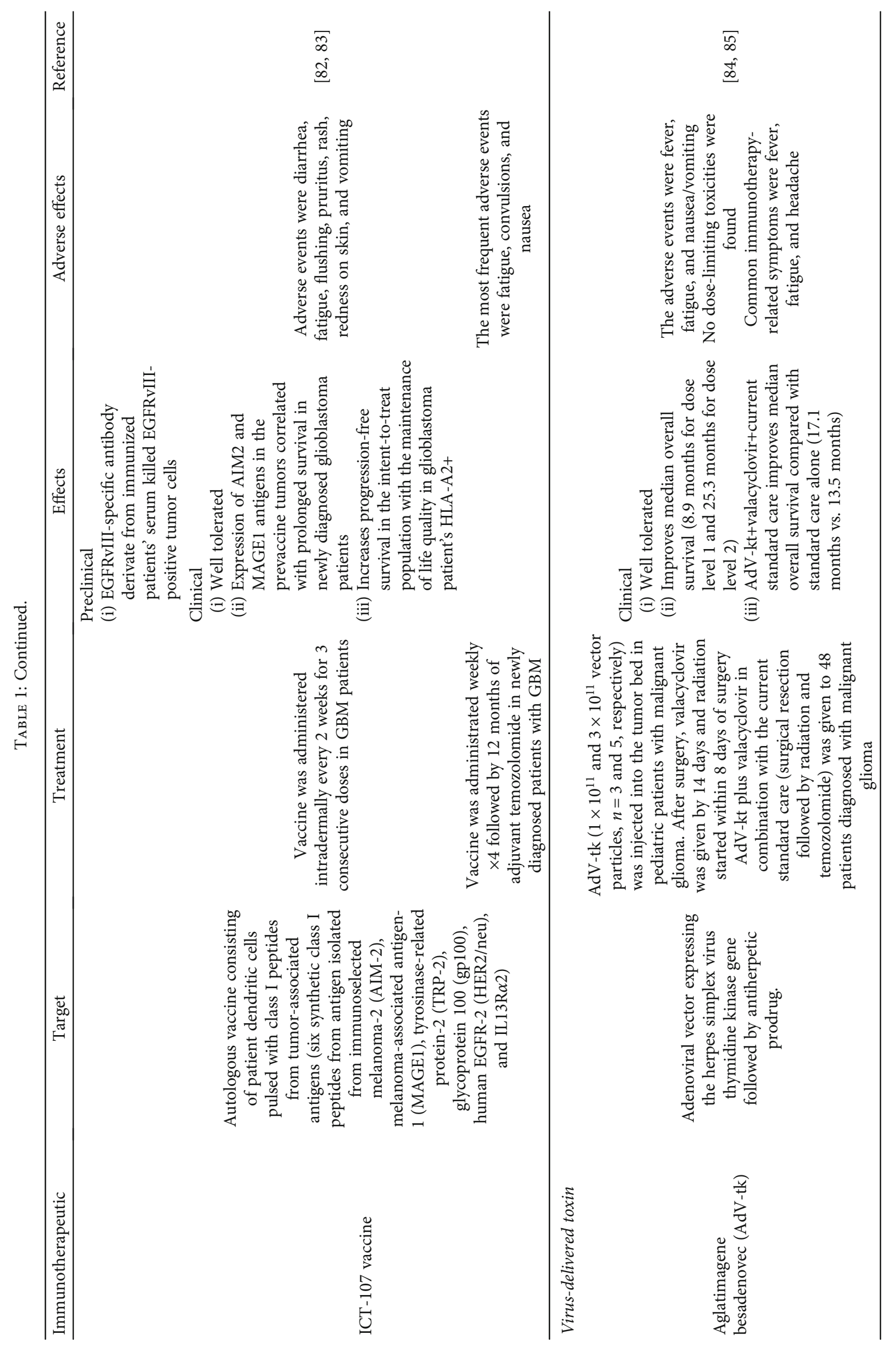




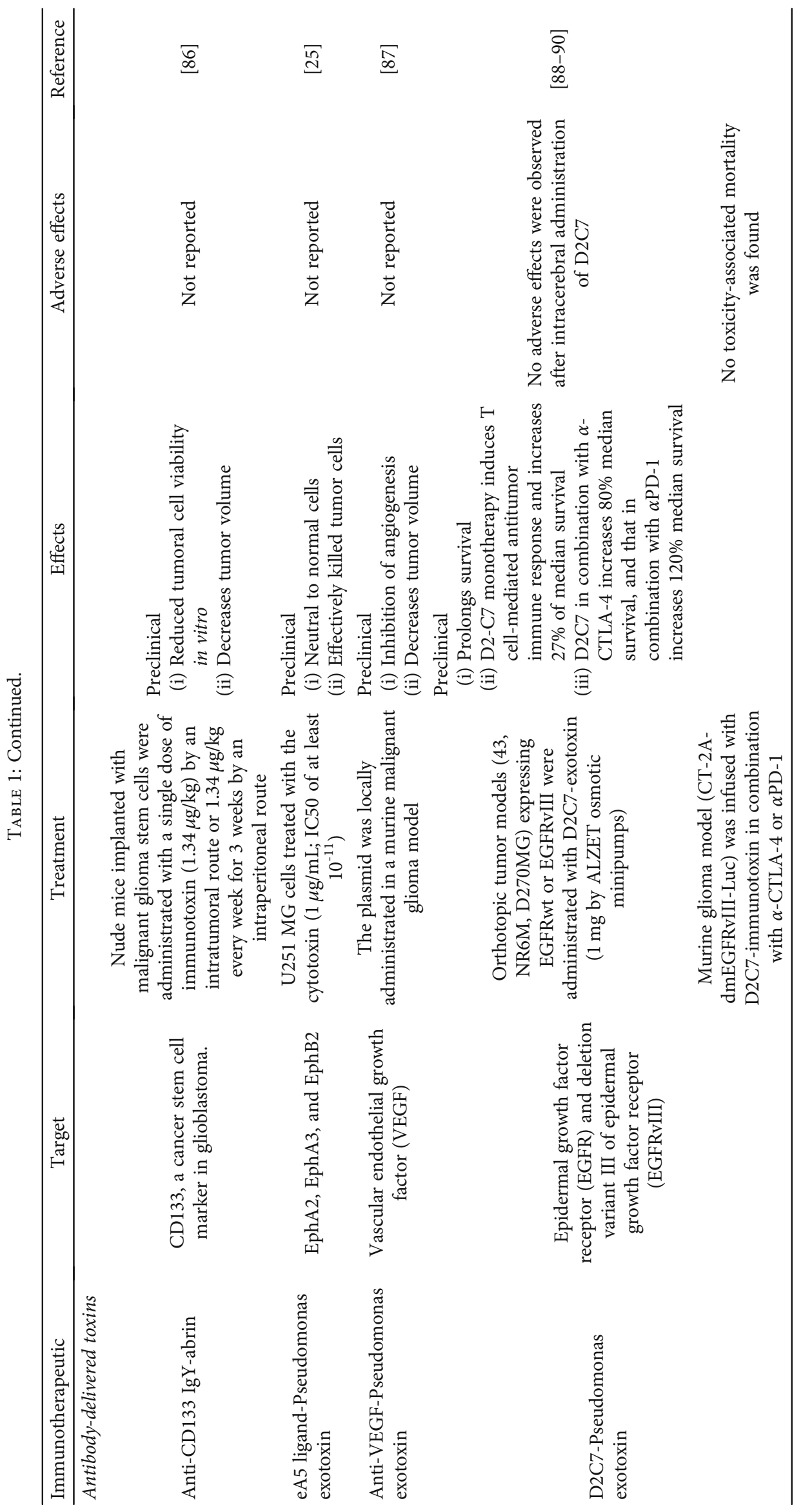




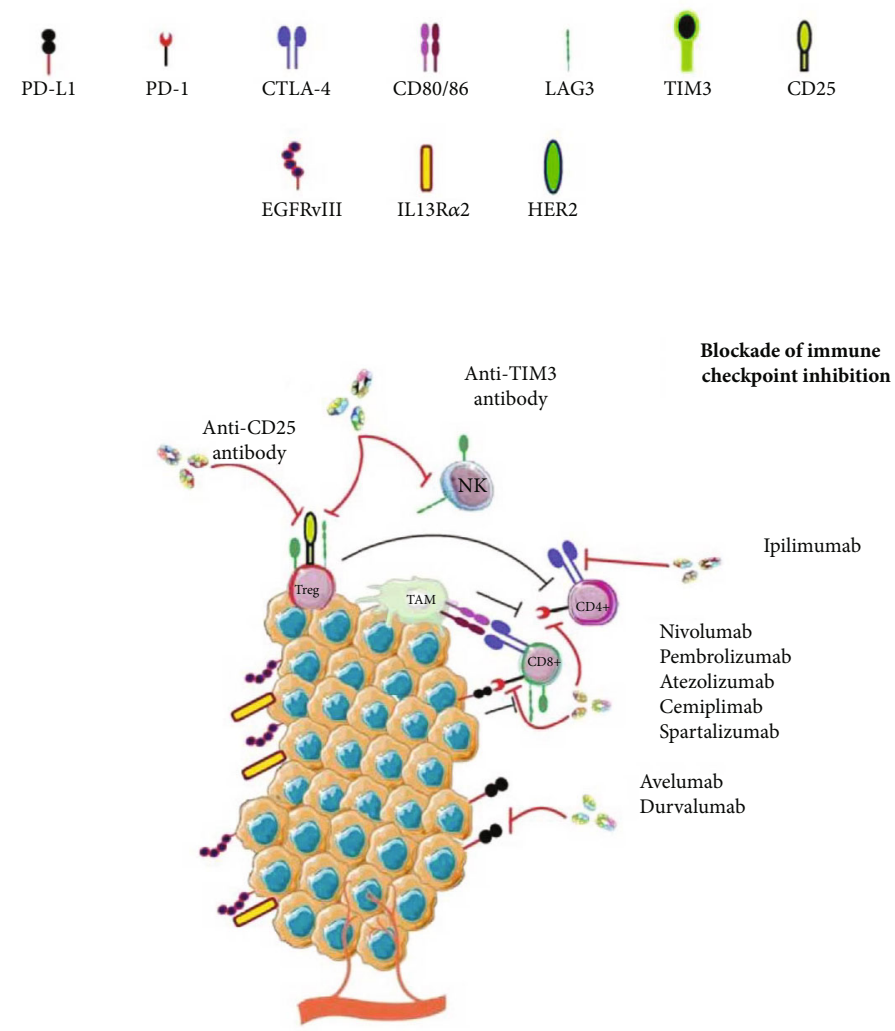

(a)

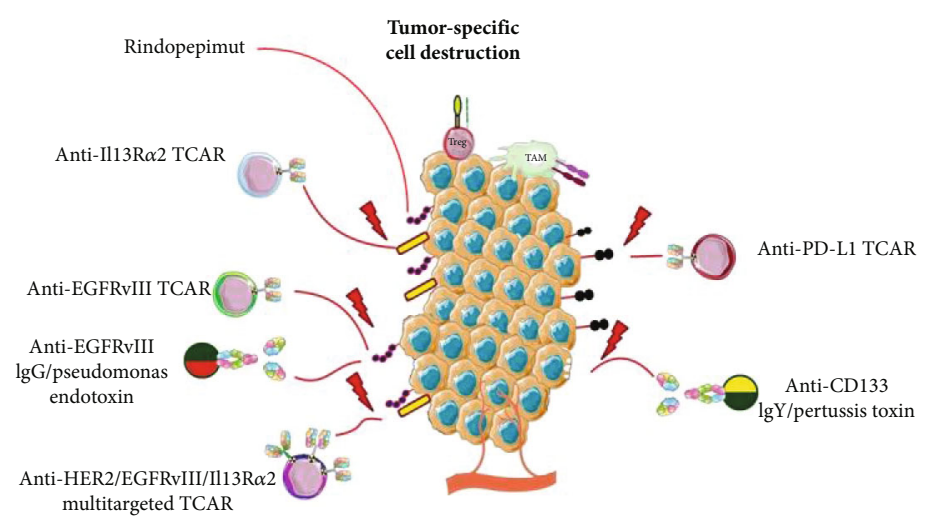

(b)

Figure 2: The immunotherapeutic approaches on GBM. (a) Monoclonal antibodies and their targets on the GBM microenvironment are aimed at blocking the circuit of proliferative signals in the tumor cells or restoring antitumor immune responses by blocking immune checkpoint signalling, inhibiting Treg populations, or stimulating cytotoxic lymphocytes. (b) CAR-Ts and immunotoxins designed for the recognition and elimination of malignant cells based on the expression of tumor-associated antigens present on GBM cells.

these neoadjuvant treatments and the differences between lymphocyte infiltration rates into tumor tissue have been shown to be related to the mutational load on the PTEN gene. GBM patients with wild-type PTEN tumor tissue reactivity showed better outcome and increased lymphocyte infiltration than those with presented PTEN mutations [48]. On the other hand, fewer clinical studies have been reported with ipilimumab in GBM patients; patients who received ipilimumab in combination with bevacizumab showed partial radiographic responses and these drugs were well tolerated [49]. The use of ipilimumab together with temozolomide is currently being tested in clinical trials (ISRCTN84434175).

In addition to the blockade of CTLA-4 and PD-1, other checkpoint molecules such as the $\mathrm{T}$ cell immunoglobulin and mucin domain-containing protein 3 (TIM3) and the lymphocyte activation gene 3 (LAG-3) have been used as targets for a monoclonal antibody in GBM clinical trials. Clinical trials on the immune checkpoint inhibitors alone may have not shown high therapeutic efficacies, but the results of the immune phenotyping demonstrated that the use of these drugs allowed initiating the reactivation of 
antitumor immune responses. However, more information is needed focused on the combinatorial effect of these neoadjuvant treatments together with the administration of the standardized drugs against GBM.

\subsection{Therapy Based on GBM-Associated Antigens and GBM} Neoantigens. Tumor-associated antigens are molecules present in normal tissues but overexpressed in malignant cells, while neoantigens are tumor-specific molecules derived from mutations in the tumor cell genome [50]. The identification of tumor neoantigens and the identification of the abnormal expression of surface proteins in tumor cells have led to the development of T lymphocytes armed with chimeric antigen receptors (CAR-Ts) and tumor-targeted vaccines to enhance tumor-specific toxicity (Table 1).

The development and efficacy of a range of CAR-Ts targeted against different surface molecules representative of GBM tissue have been challenged in patients. IL-13 receptor $\alpha 2(\mathrm{IL} 13 \mathrm{R} \alpha 2)$ is a poor patient survival prognostic indicator, which is overexpressed by more than $50 \%$ of GBM [51]. IL13R $\alpha 2$-specific CAR-Ts have been evaluated in phase I clinical trials showing the tolerability and safety of its intracranial administration. Also, it increases the necrotic volume and reduces IL3R $\alpha 2$ expression in GBM tissue compared with paired pretreatment samples as well as tumor partial remission and complete tumor remission in one of the patients enrolled in this study $[51,52]$. The EGFRvIII, a mutated form of EGFR expressed in $30 \%$ of GBM [53], is related to the increase in glioma proliferation, invasion, and therapeutic resistance [54-56]. EGFRvIII has been tested for the use of CAR-Ts and to produce peptide vaccines because it is not expressed in normal brain tissue representing an ideal therapeutic target [57]. Meanwhile, EGFRvIII-targeted CAR-Ts have been shown to infiltrate and activate within tumor tissue an early response in GBM patients. However, GBM patients have shown the overexpression of immunosuppressive markers such as PD-L1 and indoleamine-2,3-dioxygenase, together with an increase in the Treg population in tumor tissue after CAR-T administration due to the primary inflammatory response elicited by the CAR-Ts [58]. Furthermore, the engineering of CAR-Ts targeting the human epidermal growth factor receptor type 2 (HER2) has also shown promising results against GBM, showing an increase in PFS and OS means in treated patients [59].

The transplant of engineered CAR-Ts has shown promising results in the treatment of GBM; however, current treatments only have focused on the administration of single-targeted cells limiting these tools by ignoring those malignant cells which do not express the target molecule of CAR-Ts.

2.2.1. Immune Checkpoint Molecules as Targets for Engineered Lymphocytes. In addition to blocking antibodies against the immune checkpoint molecules, PD-1 has been recently exploited as a tool target of chimeric switch receptor-engineered lymphocytes. Cytotoxic lymphocytes armed with this receptor can recognize PD-1 expressed on the surface of tumor cells and can eliminate them due to the transmembrane and cytosolic domains of this receptor, corresponding to the activation domains of the protein CD28 [91]. A phase I clinical trial in recurrent and refractory GBM patients using these engineered lymphocytes showed the safety of the intravenous or intracranial administration of these cells, with increased levels of interferon- $\gamma$ and IL6 , a signature of the activation of the engineered lymphocytes [92]. These results are promising; however, further clinical studies will determine the true efficacy of these cells as a treatment against GBM (Figure 2(b)).

\subsubsection{Preclinical Studies on Next-Generation CAR-T Cells.} Multitargeted CAR-Ts for treating GBM have been started to be used in preclinical models, but evidence in clinical trials is further needed to determine their therapeutic efficacy. The development of third-generation CAR-Ts has allowed more accurate responses by modifying CAR-Ts for evasion of checkpoint inhibition as well as the expression of costimulatory molecules that allow better antitumor responses. Those have been tested against GBM, showing promising results in preclinical models. Specifically, anti-EGFRvIII CAR-Ts with a deleted expression of PD-1 have shown better antiglioma activity and longer survival in mice than in those CAR-Ts with wild-type PD-1 expression [78]. In the same line, EGFRvIII CAR-Ts expressing costimulatory molecules like CD28 or OX-40 have been shown to improve survival in an intracranial xenogenic human glioblastoma model [77]. As was mentioned above, a limitation of the use of single-targeted CAR-Ts is the elimination of just a single type of tumor cell ignoring the variability present on heterogeneous tumors such as GBM. To solve this question, the development of multiple-targeted CAR-Ts has come to be explored taking into consideration that the target should be a tumor-specific antigen to prevent off-tumor toxicities. The development of trivalent CAR-Ts specific to IL13R $\alpha 2$, the human epidermal growth factor receptor (HER-2) and EGFRvIII, was made possible by analysing interpatient variability of multiple GBM samples, showing tumor cellspecific cytotoxicity and tumor remission in vitro and in vivo models [79].

2.3. GBM-Associated Antigen-Targeted and NeoantigenTargeted Drugs. The combination of different elements by genetic engineering has provided the development of several immunotherapeutic tools that have been tested against GBM. The production of immunotoxins, the antigenbinding region of immunoglobulins fused with cytotoxic agents, has shown preclinical efficacy in the treatment of GBM. The immunotoxins' utility and specificity are dictated by the targeted tumor antigen, and in recent years, many targets have been explored for GBM, mainly focused on the receptor for transferrin, transforming growth factor alpha (TGF- $\alpha$ ), IL-13, IL-4, and EGFRvIII. The common toxins used to produce immunotoxins are the Pseudomonas exotoxin A and diphtheria toxin (revised review [93, 94]).

Herein, we describe the recent advances in immunotoxins against GBM in the last years. One of the targets in GBM is the cancer stem cells (CSC), which are a small population of slow-dividing and self-renewing glioma cells. The glioma stem cells express the antigen CD133, which has been related 
to tumor resistance to chemotherapy [95]. Recently, an $\operatorname{IgY}$ immunotoxin was produced against the $\mathrm{CD} 133+$ subpopulation of GBM CSC. This avian anti-CD133 IgY was fused with the A chain of the abrin toxin with the purpose to inactivate the ribosome. The anti-CD133-IgY-abrine showed to reduce cell viability of C6 CSC in vitro and decreased tumor volume after implantation of malignant glioma stem cells in vivo, representing a low-cost tool for the treatment of GBM [86]. Another target expressed in glioma stem cells is the Eph receptors, which are part of the receptor tyrosine kinase family. The ephrinA5 (eA5), a ligand that binds with EphA3, EphA2, and EphB2 receptors, was conjugated to Pseudomonas exotoxin A showing to kill glioblastoma cells in vitro [25]. The calcitonin receptor has been recently considered a target for GBM since it is expressed in a high percentage of GBM human biopsies [96]. The anti-calcitonin receptor antibody conjugated to the plant toxins dianthin-30 or gelonin showed cytotoxicity in several high-grade glioma cell lines, demonstrating that this receptor could be an effective target [97]. Other immunotoxins studied in GBM are directed to the surface proteins overexpressed in GBM cells such as EFGRvIII, VEGF, or ephrin receptors [25, 87-89], and their use in combination with other immunotherapeutic tools such as the blockade of checkpoint molecules, PD-1 or CTLA-4, demonstrated tumor clearance in immunocompetent animals [89]. Furthermore, the development of multiple-targeted immunotoxins also has shown promising results for their use against GBM [98]. As with multitargeted CAR-Ts, the use of multidirected immunotoxins represents an advantage over the single-targeted tools designed, due to their capacity to recognize a wider subset of malignant cells, while the combination of different immunotherapeutic strategies also represents an advantage because of the presence of antitumor toxins, besides the fact that the blockade of immune checkpoint inhibition provides a microenvironmental change favorable to the tumor elimination.

2.4. Therapeutic Vaccination against GBM. Vaccination is a type of immunotherapy focused on the tumor-associated antigens. Antigens for cancer vaccines should be expressed only by malignant cells to kill specifically tumor cells. In GBM, the EGFRvIII-targeted vaccine Rindopepimut, a selective tumor-specific antigen peptide vaccine targeting the EGFRvIII mutation, has demonstrated antitumor immune activation in GBM patients as well as longer OS than that of temozolomide-treated patients [99]. However, this vaccine showed no differences in OS compared with standard treatments in phase III clinical trials [100]. Additionally, Rindopepimut has been shown to eliminate specifically cells expressing EGFRvIII, and when it is administrated with the adjuvant granulocyte-macrophage colonystimulating factor and treated with the standard temozolomide, dosing maintenance therapy increases median PFS and OS [101]. A recent phase II study conducted in bevacizumab-naïve patients with recurrent EGFRvIIIpositive GBM showed that the addition of Rindopepimut improves OS and induced robust de novo anti-EGFRvIII antibody titers; however, additional studies should be carried out to confirm these results due the small sample size [81].
ICT-107 is another vaccine tested for GBM that consists in an autologous dendritic cell pulsed ex vivo with tumor and CSC antigens (AIM-2, HLA-A2, HER2, TRP-2, gp100, and IL13R $\alpha 2$ ). A clinical study using ICT-107 following conventional treatment showed a nonsignificant trend toward increased PFS. Also, the use of ICT-107 vaccine showed a reduction in CD133 expression in some GBM patients [82].

On the other hand, a preclinical study was focused on the immunogenic damage induced by radiation producing damage-associated molecular patterns (DAMPs), which activate the innate immune system and latterly the adaptive immune response. In this line, recently it was demonstrated that the administration of microvesicles released after C6 cells were irradiated reduced more than 50\% tumor volume, increased the infiltrating $\mathrm{T}$ lymphocytes, and promoted the apoptosis of glioma cells compared with the group that was not immunized with these microvesicles [102]. The use of microvesicles derived from irradiated tumor cells could be a new approach to glioblastoma treatment.

2.5. Oncolytic Viruses as Activators of Tumor Elimination. In recent years, the use of oncolytic viruses has gained importance as a tool for the treatment of various solid tumors due to their tropism and selective replication in tumor cells. Evidence shows that oncolytic viruses are useful by reducing tumor bulk but also in the immune reactivation of antitumor responses [103]. The efficacy of oncolytic virus against tumors is dependent on their ability to infect and kill tumor cells specifically as well as to activate the antitumor immune response (innate and adaptive). The oncolytic viruses activate the innate immune responses through tumorassociated antigens (TAAs), damage-associated molecular patterns (DAMPs), and pathogen-associated molecular patterns produced by immunogenic cell death (PAMPs). Both DAMPs and PAMPs activate the pattern recognition receptors (PRRs) expressed in the innate immune cells, such as toll-like receptors, enhancing their phagocytic and antigen presentation activities, promoting their activation and maturation, and inducing the shift towards M1 phenotypes, which contribute to a robust antitumor immune response [104-106]. Preclinical studies have evidenced the efficacy of oncolytic viruses like measles virus, herpes simplex virus, parvovirus, adenovirus, and Zika virus against GBM [107-111]. In 2018, it was reported that a live-attenuated Zika virus vaccine killed human glioma stem cells in vitro, which was also related to both a reduction in the intracerebral tumor growth and prolongation of animal survival, but it was observed that this vaccine activates the antitumor immunity [112]. Recently, it was described that Zika virus increases the CD8+ T cell infiltration in the tumor microenvironment and the beneficial effects on survival and tumor volume induced by Zika virus, which are enhanced by its combination with anti-PD-1 treatment [113]. Moreover, it was described that the oncolytic type I herpes simplex virus administration in a mouse GBM model led to the infiltration of both tumor antigen-specific and viral antigen-specific CD8+ T cells, which correlated with tumor reduction [104].

In the case of clinical trials, the administration of intratumorally attenuated parvovirus resulted in a slight increase 
in the median OS; however, there is an increased number of infiltrating lymphocytes and IFN- $\gamma$ levels [114]. The use of the adenoviral vector aglatimagene besadenovec has shown successful results prolonging the median OS of GBM patients to 25 months [85]. However, more clinical trials are needed to investigate the safety and efficacy of the oncolytic virus as a therapy for GBM.

\subsection{Tryptophan Catabolism as a Target for Antitumor} Immune Activation. In addition to the use of anti-PD1/PD-L1 or anti-CTLA-4 antibodies, the search of immune inhibitory blockade mechanisms has led to the study of metabolic pathways used by malignant cells to shape tumor microenvironment and to induce immune modulation. One of these routes that become to receive attention is the catabolism of tryptophan through the kynurenine pathway (KP). Evidence shows that one of the limiting enzymes of the $\mathrm{KP}$, the indoleamine-2,3-dioxygenase (IDO), is overexpressed in different neoplasms including GBM, and its expression levels correlate with increased tumor-infiltrated TAM and Treg and with patient poor prognosis [115-118]. The use of pharmacological inhibitors of IDO has shown promising results in preclinical models when combined with temozolomide or anti-PD-L1 antibodies [119-121]. In this line, it has been observed that the modulation of IDO by its inhibitor 1-methyl-l-tryptophan or knocking down IDO cells, results in a reduction of tumor growth and a longer survival period. These effects were synergistic with the use of temozolomide [120]. Recently, it was shown that dinaciclib (cyclin-dependent kinase inhibitor) downregulates KPrelated genes such as IDO1, TDO2, KYAT1-4, and KMO in patient-derived GBM cell lines [122].

Additionally, L-kynurenine, the product of Trp degradation by IDO or TDO, has been involved in the GBM pathology since the kynurenine-AhR pathway can contribute to increasing the growth and motility of tumor cells and suppresses the immune response. Furthermore, the KPderived metabolites have been implied with the generation of Tregs and the induction of apoptosis in lymphocyte subsets [123]; thus, the accumulation of these molecules could be contributing to the immunosuppressive environment within the tumor; however, the dynamics of the production of these metabolites and the expression of other KP enzymes remain less studied. In this context, our group recently found a kynurenine monooxygenase (KMO) expression and activity in human glioblastoma cell culture as well as in the GBM patient's samples. This novel finding suggests a possible KMO participation in the immunosuppressive environment since KMO is not normally expressed in astrocytes (manuscript in preparation). This information could be useful for the development of new immunotherapeutic strategies employed against GBM.

2.7. Success of Immunotherapies: What Does It Depend on? As mentioned above, GBM remains as an incurable disease and the low impact of current protocols for the treatment of GBM has been associated with the high prevalence of tumor recurrence mainly due to the development of drug resistance, intratumoral heterogeneity, and the given pheno- typic plasticity by CSC able to change their metabolic activity under stress conditions [124-129]. All these differences are a consequence of genetic alterations that occur in malignant cells that make GBM genetically diverse within a single tumor and between different tumors [3, 130, 131]. The genomic profiling of GBM has led to the identification of common mutations and neoantigens and to the proposal of the classification of GBM into four subtypes [3, 130, 132]. In GBM, the most common genetic alterations are the mutation of the enzyme isocitrate dehydrogenase (IDH) of which IDH $^{\text {mut }}$ tumors present a better prognosis; with the unmethylation of the 8-methylguanosine methyltransferase (MGMT) promoter, GBM with methylated MGMT show a better prognosis than that with unmethylated MGMT and EGFR amplification [130].

In the case of the different immunotherapeutic approaches reviewed here that are on clinical trials, it is noteworthy that some of them report differences in the clinical outcomes based on genotypic and phenotypic characteristics of the patients. It was demonstrated that patients who showed a long-term follow-up after treatment with antibodies targeted to immune checkpoint molecules had methylation of the MGMT promoter, a marker of good prognosis of GBM [43, 45]. IDH ${ }^{\mathrm{wt}}$ patients who showed a good response to these antibodies also showed enrichment for MAPK mutations, while nonresponsive patients showed enrichment of PTEN mutations [48].

The use of CAR-Ts and peptide vaccines against tumorspecific antigens and neoantigens has demonstrated clearance of tumor cells that carry such targets [51, 59, 81]; however, these immune strategies could act as a selective pressure by not eliminating the portion of malignant cells that do not carry the antigenic target [133]. Therefore, the ideal would be to perform more in-depth molecular screenings or the use of multiple-target strategies.

Finally, the genetic profiling of patient-derived tumors could show useful information on which therapeutic strategies would be optimal for an individual but also to monitor how different tumors respond to a certain treatment.

\section{Conclusions}

Herein, the immunotherapeutic strategies that are currently accepted for GBM treatment and those which are in the first stages of the clinical study with promising results were discussed. Until now, preclinical studies have led to the expansion of the knowledge of the immunological landscape occurring in GBM, allowing the development of more accurate tools that stimulate an antitumor response. On the other hand, the immunotherapeutic strategies tested in GBM patients have not shown the efficient results expected in terms of OS; however, evidence of antitumor immune activation and increase in tumor progression-free survival are promising traits for further development of different immunological strategies to combat GBM. Furthermore, the use of combined immunotherapy strategies to combat malignant neoplasms shows encouraging results in preclinical models that lay the foundation for the beginning of its study in clinical protocols. A combination of schemes that override 
tumor-induced immunosuppressive mechanisms, together with those strategies that potentiate the activation of antitumor immune response, is worthy of attention. Deeper research of the immune behavior of GBM could lead to the development of more efficient tools for the treatment of this disease and therefore to the clinical acceptance of these strategies for a generalized treatment program to combat GBM.

\section{Conflicts of Interest}

The authors declare that there is no conflict of interest regarding the publication of this paper.

\section{Acknowledgments}

This study was performed in partial fulfillment of the requirements for the Ph.D. degree of G.I.V.C. on the field of Experimental Biology in the Posgrado en Ciencias Biológicas at the Universidad Nacional Autónoma de México. G.I.V.C. is a scholarship holder of CONACyT-México (308052) in the Graduate Program in Biological Science, UNAM. This research was partially funded by Consejo de Investigación sobre Salud y Cerveza de México, A. C. Fomento a la Investigación 2019 (grant number 110-19).

\section{References}

[1] R. Stupp, M. Brada, M. J. van den Bent, J. C. Tonn, G. Pentheroudakis, and ESMO Guidelines Working Group, "High-grade glioma: ESMO Clinical Practice Guidelines for diagnosis, treatment and follow-up $\dagger$," Annals of oncology, vol. 25, Supplement 3, pp. iii93-ii101, 2014.

[2] R. Stupp, W. P. Mason, M. J. van den Bent et al., "Radiotherapy plus concomitant and adjuvant temozolomide for glioblastoma," The New England Journal of Medicine, vol. 352, no. 10, pp. 987-996, 2005.

[3] R. G. Verhaak, K. A. Hoadley, E. Purdom et al., "Integrated genomic analysis identifies clinically relevant subtypes of glioblastoma characterized by abnormalities in PDGFRA, IDH1, EGFR, and NF1," Cancer Cell, vol. 17, no. 1, pp. 98$110,2010$.

[4] M. L. Broekman, S. L. N. Maas, E. R. Abels, T. R. Mempel, A. M. Krichevsky, and X. O. Breakefield, "Multidimensional communication in the microenvirons of glioblastoma," Nature Reviews. Neurology, vol. 14, no. 8, pp. 482-495, 2018.

[5] G. A. Rabinovich, D. Gabrilovich, and E. M. Sotomayor, "Immunosuppressive strategies that are mediated by tumor cells," Annual Review of Immunology, vol. 25, no. 1, pp. 267-296, 2007.

[6] A. Waziri, "Glioblastoma-derived mechanisms of systemic immunosuppression," Neurosurgery Clinics of North America, vol. 21, no. 1, pp. 31-42, 2010.

[7] P. Perng and M. Lim, "Immunosuppressive mechanisms of malignant gliomas: parallels at non-CNS sites," Frontiers in Oncology, vol. 5, p. 153, 2015.

[8] A. Gieryng, D. Pszczolkowska, K. A. Walentynowicz, W. D. Rajan, and B. Kaminska, "Immune microenvironment of gliomas," Laboratory Investigation, vol. 97, no. 5, pp. 498-518, 2017.
[9] B. Wahid, A. Ali, S. Rafique et al., "An overview of cancer immunotherapeutic strategies," Immunotherapy, vol. 10, no. 11, pp. 999-1010, 2018.

[10] R. J. Diaz, S. Ali, M. G. Qadir, M. I. de la Fuente, M. E. Ivan, and R. J. Komotar, "The role of bevacizumab in the treatment of glioblastoma," Journal of Neuro-Oncology, vol. 133, no. 3, pp. 455-467, 2017.

[11] N. Hata, M. Mizoguchi, D. Kuga et al., "First-line bevacizumab contributes to survival improvement in glioblastoma patients complementary to temozolomide," Journal of Neuro-Oncology, vol. 146, no. 3, pp. 451-458, 2020.

[12] Z. An, O. Aksoy, T. Zheng, Q. W. Fan, and W. A. Weiss, "Epidermal growth factor receptor and EGFRvIII in glioblastoma: signaling pathways and targeted therapies," Oncogene, vol. 37, no. 12, pp. 1561-1575, 2018.

[13] D. A. Reardon, S. Turner, K. B. Peters et al., "A review of VEGF/VEGFR-targeted therapeutics for recurrent glioblastoma," Journal of the National Comprehensive Cancer Network, vol. 9, no. 4, pp. 414-427, 2011.

[14] X. J. du, X. M. Li, L. B. Cai et al., "Efficacy and safety of nimotuzumab in addition to radiotherapy and temozolomide for cerebral glioblastoma: a phase II multicenter clinical trial," Journal of Cancer, vol. 10, no. 14, pp. 3214-3223, 2019.

[15] M. T. Solomon, N. Miranda, E. Jorrín et al., "Nimotuzumab in combination with radiotherapy in high grade glioma patients: a single institution experience," Cancer Biology \& Therapy, vol. 15, no. 5, pp. 504-509, 2014.

[16] M. Westphal, O. Heese, J. P. Steinbach et al., "A randomised, open label phase III trial with nimotuzumab, an antiepidermal growth factor receptor monoclonal antibody in the treatment of newly diagnosed adult glioblastoma," European Journal of Cancer, vol. 51, no. 4, pp. 522-532, 2015.

[17] Y. Nitta, S. Shimizu, Y. Shishido-Hara, K. Suzuki, Y. Shiokawa, and M. Nagane, "Nimotuzumab enhances temozolomide-induced growth suppression of glioma cells expressing mutant EGFR in vivo," Cancer Medicine, vol. 5, no. 3, pp. 486-499, 2016.

[18] S. H. Yang, Y. K. Hong, S. S. Jeun et al., “Assessment of cetuximab efficacy by bioluminescence monitoring of intracranial glioblastoma xenograft in mouse," Journal of Neuro-Oncology, vol. 95, no. 1, pp. 23-28, 2009.

[19] P. Y. Wen, D. Schiff, T. F. Cloughesy et al., "A phase II study evaluating the efficacy and safety of AMG 102 (rilotumumab) in patients with recurrent glioblastoma," Neuro-Oncology, vol. 13, no. 4, pp. 437-446, 2011.

[20] K. Rex, X. Z. Lewis, S. Gobalakrishnan et al., "Evaluation of the antitumor effects of rilotumumab by PET imaging in a U-87 MG mouse xenograft model," Nuclear Medicine and Biology, vol. 40, no. 4, pp. 458-463, 2013.

[21] I. M. Buchanan, T. Scott, A. T. Tandle et al., "Radiosensitization of glioma cells by modulation of Met signalling with the hepatocyte growth factor neutralizing antibody, AMG102," Journal of Cellular and Molecular Medicine, vol. 15, no. 9, pp. 1999-2006, 2011.

[22] H. T. Jun, J. Sun, K. Rex et al., "AMG 102, a fully human antihepatocyte growth factor/scatter factor neutralizing antibody, enhances the efficacy of temozolomide or docetaxel in U-87 MG cells and xenografts," Clinical Cancer Research, vol. 13, no. 22, pp. 6735-6742, 2007.

[23] E. S. Mittra, H. Fan-Minogue, F. I. Lin et al., "Preclinical efficacy of the anti-hepatocyte growth factor antibody 
ficlatuzumab in a mouse brain orthotopic glioma model evaluated by bioluminescence, PET, and MRI," Clinical Cancer Research, vol. 19, no. 20, pp. 5711-5721, 2013.

[24] T. Cloughesy, G. Finocchiaro, C. Belda-Iniesta et al., "Randomized, double-blind, placebo-controlled, multicenter phase II study of onartuzumab plus bevacizumab versus placebo plus bevacizumab in patients with recurrent glioblastoma: efficacy, safety, and hepatocyte growth factor and $\mathrm{O}^{6}$ methylguanine-DNA methyltransferase biomarker analyses," Journal of Clinical Oncology, vol. 35, no. 3, pp. 343-351, 2017.

[25] S. Ferluga, C. M. L. Tomé, D. M. Herpai, R. D'Agostino, and W. Debinski, "Simultaneous targeting of Eph receptors in glioblastoma," Oncotarget, vol. 7, no. 37, article 10978, pp. 59860-59876, 2016.

[26] L. F. Porrata, M. R. Litzow, and S. N. Markovic, "Immune reconstitution after autologous hematopoietic stem cell transplantation," Mayo Clinic Proceedings, vol. 76, no. 4, pp. 407412, 2001.

[27] O. Yeku, X. Li, and R. J. Brentjens, "Adoptive T-cell therapy for solid tumors," American Society of Clinical Oncology Educational Book, vol. 37, no. 37, pp. 193-204, 2017.

[28] H. Allahyari, S. Heidari, M. Ghamgosha, P. Saffarian, and J. Amani, "Immunotoxin: a new tool for cancer therapy," Tumor Biology, vol. 39, no. 2, 2017.

[29] Y. Hattori, "Development of non-viral vector for cancer gene therapy,” Yakugaku Zasshi, vol. 130, no. 7, pp. 917-923, 2010.

[30] H. Fukuhara, Y. Ino, and T. Todo, "Oncolytic virus therapy: a new era of cancer treatment at dawn," Cancer Science, vol. 107, no. 10, pp. 1373-1379, 2016.

[31] E. I. Buchbinder and A. Desai, "CTLA-4 and PD-1 pathways: similarities, differences, and implications of their inhibition," American Journal of Clinical Oncology, vol. 39, no. 1, pp. 98106, 2016.

[32] A. V. Collins, D. W. Brodie, R. J. Gilbert et al., "The interaction properties of costimulatory molecules revisited," Immunity, vol. 17, no. 2, pp. 201-210, 2002.

[33] F. Pagès, M. Ragueneau, R. Rottapel et al., "Binding of phosphatidyl-inositol-3-OH kinase to $\mathrm{CD} 28$ is required for T-cell signalling," Nature, vol. 369, no. 6478, pp. 327-329, 1994.

[34] S. C. Wei, C. R. Duffy, and J. P. Allison, "Fundamental mechanisms of immune checkpoint blockade therapy," Cancer Discovery, vol. 8, no. 9, pp. 1069-1086, 2018.

[35] M. J. Selby, J. J. Engelhardt, M. Quigley et al., “Anti-CTLA-4 antibodies of IgG2a isotype enhance antitumor activity through reduction of intratumoral regulatory T cells," Cancer Immunology Research, vol. 1, no. 1, pp. 32-42, 2013.

[36] V. A. Boussiotis, "Molecular and biochemical aspects of the PD-1 checkpoint pathway," The New England Journal of Medicine, vol. 375, no. 18, pp. 1767-1778, 2016.

[37] P. C. Tumeh, C. L. Harview, J. H. Yearley et al., "PD-1 blockade induces responses by inhibiting adaptive immune resistance," Nature, vol. 515, no. 7528, pp. 568571, 2014.

[38] R. J. Motzer, N. M. Tannir, D. F. McDermott et al., "Nivolumab plus ipilimumab versus sunitinib in advanced renal-cell carcinoma," The New England Journal of Medicine, vol. 378, no. 14, pp. 1277-1290, 2018.

[39] J. Larkin, V. Chiarion-Sileni, R. Gonzalez et al., "Five-year survival with combined nivolumab and ipilimumab in advanced melanoma," The New England Journal of Medicine, vol. 381, no. 16, pp. 1535-1546, 2019.
[40] M. D. Hellmann, T. E. Ciuleanu, A. Pluzanski et al., "Nivolumab plus ipilimumab in lung cancer with a high tumor mutational burden," The New England Journal of Medicine, vol. 378, no. 22, pp. 2093-2104, 2018.

[41] H. A. Tawbi, P. A. Forsyth, A. Algazi et al., "Combined nivolumab and ipilimumab in melanoma metastatic to the brain," The New England Journal of Medicine, vol. 379, no. 8, pp. 722-730, 2018.

[42] A. Omuro, G. Vlahovic, M. Lim et al., "Nivolumab with or without ipilimumab in patients with recurrent glioblastoma: results from exploratory phase I cohorts of CheckMate 143," Neuro-Oncology, vol. 20, no. 5, pp. 674-686, 2018.

[43] K. A. Schalper, M. E. Rodriguez-Ruiz, R. Diez-Valle et al., "Neoadjuvant nivolumab modifies the tumor immune microenvironment in resectable glioblastoma," Nature Medicine, vol. 25, no. 3, pp. 470-476, 2019.

[44] M. Mantica, A. Pritchard, F. Lieberman, and J. Drappatz, "Retrospective study of nivolumab for patients with recurrent high grade gliomas," Journal of Neuro-Oncology, vol. 139, no. 3, pp. 625-631, 2018.

[45] D. A. Reardon, A. A. Brandes, A. Omuro et al., "Effect of nivolumab vs bevacizumab in patients with recurrent glioblastoma: the CheckMate 143 phase 3 randomized clinical trial," JAMA Oncology, vol. 6, no. 7, pp. 1003-1010, 2020.

[46] T. F. Cloughesy, A. Y. Mochizuki, J. R. Orpilla et al., "Neoadjuvant anti-PD-1 immunotherapy promotes a survival benefit with intratumoral and systemic immune responses in recurrent glioblastoma," Nature Medicine, vol. 25, no. 3, pp. 477-486, 2019.

[47] J. de Groot, M. Penas-Prado, K. Alfaro-Munoz et al., "Window-of-opportunity clinical trial of pembrolizumab in patients with recurrent glioblastoma reveals predominance of immune-suppressive macrophages," Neuro-Oncology, vol. 22, no. 4, pp. 539-549, 2020.

[48] J. Zhao, A. X. Chen, R. D. Gartrell et al., "Immune and genomic correlates of response to anti-PD-1 immunotherapy in glioblastoma," Nature Medicine, vol. 25, no. 3, pp. 462-469, 2019.

[49] T. Carter, H. Shaw, D. Cohn-Brown, K. Chester, and P. Mulholland, "Ipilimumab and bevacizumab in glioblastoma," Clinical Oncology (Royal College of Radiologists), vol. 28, no. 10, pp. 622-626, 2016.

[50] L. Li, S. P. Goedegebuure, and W. E. Gillanders, "Preclinical and clinical development of neoantigen vaccines," Annals of Oncology, vol. 28, supplement 12, pp. xii11-xii17, 2017.

[51] C. E. Brown, B. Badie, M. E. Barish et al., "Bioactivity and safety of IL13R $\alpha 2$-redirected chimeric antigen receptor CD8 $+\mathrm{T}$ cells in patients with recurrent glioblastoma," Clinical Cancer Research, vol. 21, no. 18, pp. 4062-4072, 2015.

[52] C. E. Brown, D. Alizadeh, R. Starr et al., "Regression of glioblastoma after chimeric antigen receptor T-cell therapy," The New England Journal of Medicine, vol. 375, no. 26, pp. 2561-2569, 2016.

[53] A. J. Ekstrand, N. Longo, M. L. Hamid et al., "Functional characterization of an EGF receptor with a truncated extracellular domain expressed in glioblastomas with EGFR gene amplification," Oncogene, vol. 9, no. 8, pp. 2313-2320, 1994.

[54] A. Lal, C. A. Glazer, H. M. Martinson et al., "Mutant epidermal growth factor receptor up-regulates molecular effectors of tumor invasion," Cancer Research, vol. 62, no. 12, pp. 3335-3339, 2002. 
[55] R. Nishikawa, X. D. Ji, R. C. Harmon et al., "A mutant epidermal growth factor receptor common in human glioma confers enhanced tumorigenicity," Proceedings of the National Academy of Sciences of the United States of America, vol. 91, no. 16, pp. 7727-7731, 1994.

[56] G. Lammering, T. H. Hewit, M. Holmes et al., "Inhibition of the type III epidermal growth factor receptor variant mutant receptor by dominant-negative EGFR-CD533 enhances malignant glioma cell radiosensitivity," Clinical Cancer Research, vol. 10, no. 19, pp. 6732-6743, 2004.

[57] C. J. Wikstrand, L. P. Hale, S. K. Batra et al., "Monoclonal antibodies against EGFRvIII are tumor specific and react with breast and lung carcinomas and malignant gliomas," Cancer Research, vol. 55, no. 14, pp. 3140-3148, 1995.

[58] D. M. O’Rourke, M. P. Nasrallah, A. Desai et al., “A single dose of peripherally infused EGFRvIII-directed CAR T cells mediates antigen loss and induces adaptive resistance in patients with recurrent glioblastoma," Science translational medicine, vol. 9, no. 399, 2017.

[59] N. Ahmed, V. Brawley, M. Hegde et al., "HER2-specific chimeric antigen receptor-modified virus-specific $\mathrm{T}$ cells for progressive glioblastoma: a phase 1 dose-escalation trial," JAMA Oncology, vol. 3, no. 8, pp. 1094-1101, 2017.

[60] R. V. Lukas, J. Rodon, K. Becker et al., "Clinical activity and safety of atezolizumab in patients with recurrent glioblastoma," Journal of Neuro-Oncology, vol. 140, no. 2, pp. 317328, 2018.

[61] G. Awada, L. Ben Salama, J. de Cremer et al., “Axitinib plus avelumab in the treatment of recurrent glioblastoma: a stratified, open-label, single-center phase 2 clinical trial (GliAvAx)," Journal for immunotherapy of cancer, vol. 8, no. 2, article e001146, 2020.

[62] S. Harris-Bookman, D. Mathios, A. M. Martin et al., "Expression of LAG-3 and efficacy of combination treatment with anti-LAG-3 and anti-PD-1 monoclonal antibodies in glioblastoma," International Journal of Cancer, vol. 143, no. 12, pp. 3201-3208, 2018.

[63] J. E. Kim, M. A. Patel, A. Mangraviti et al., "Combination therapy with anti-PD-1, anti-TIM-3, and focal radiation results in regression of murine gliomas," Clinical Cancer Research, vol. 23, no. 1, pp. 124-136, 2017.

[64] J. H. Sampson, R. J. Schmittling, G. E. Archer et al., "A pilot study of IL-2R $\alpha$ blockade during lymphopenia depletes regulatory T-cells and correlates with enhanced immunity in patients with glioblastoma," PLoS One, vol. 7, no. 2, article e31046, 2012.

[65] J. Miska, A. Rashidi, A. L. Chang et al., "Anti-GITR therapy promotes immunity against malignant glioma in a murine model," Cancer Immunology, Immunotherapy, vol. 65, no. 12, pp. 1555-1567, 2016.

[66] M. A. Patel, J. E. Kim, D. Theodros et al., “Agonist anti-GITR monoclonal antibody and stereotactic radiation induce immune-mediated survival advantage in murine intracranial glioma," Journal for Immunotherapy of Cancer, vol. 4, no. 1, p. 28, 2016.

[67] Z. Belcaid, J. A. Phallen, J. Zeng et al., "Focal radiation therapy combined with 4-1BB activation and CTLA-4 blockade yields long-term survival and a protective antigen-specific memory response in a murine glioma model," PLoS One, vol. 9, no. 7, article e101764, 2014.

[68] C. Kühnöl, M. Herbarth, J. Föll, M. S. Staege, and C. Kramm, "CD137 stimulation and p38 MAPK inhibition improve reac- tivity in an in vitro model of glioblastoma immunotherapy," Cancer Immunology, Immunotherapy, vol. 62, no. 12, pp. 1797-1809, 2013.

[69] P. C. Gedeon, T. H. Schaller, S. K. Chitneni et al., "A rationally designed fully human EGFRvIII:CD3-targeted bispecific antibody redirects human $\mathrm{T}$ cells to treat patient-derived intracerebral malignant glioma," Clinical Cancer Research, vol. 24, no. 15, pp. 3611-3631, 2018.

[70] B. D. Choi, C. T. Kuan, M. Cai et al., "Systemic administration of a bispecific antibody targeting EGFRvIII successfully treats intracerebral glioma," Proceedings of the National Academy of Sciences of the United States of America, vol. 110, no. 1, pp. 270-275, 2013.

[71] D. R. Negri, E. Tosi, O. Valota et al., "In vitro and in vivo stability and anti-tumour efficacy of an anti- EGFR/anti-CD3 $\mathrm{F}\left(\mathrm{ab}^{\prime}\right)_{2}$ bispecific monoclonal antibody," British Journal of Cancer, vol. 72, no. 4, pp. 928-933, 1995.

[72] J. Kloepper, L. Riedemann, Z. Amoozgar et al., “Ang-2/VEGF bispecific antibody reprograms macrophages and resident microglia to anti-tumor phenotype and prolongs glioblastoma survival," Proceedings of the National Academy of Sciences of the United States of America, vol. 113, no. 16, pp. 4476-4481, 2016.

[73] A. C. Filley, M. Henriquez, and M. Dey, "Recurrent glioma clinical trial, CheckMate-143: the game is not over yet," Oncotarget, vol. 8, no. 53, pp. 91779-91794, 2017.

[74] J. Park, C. G. Kim, J. K. Shim et al., "Effect of combined antiPD-1 and temozolomide therapy in glioblastoma," Oncoimmunology, vol. 8, no. 1, article e1525243, 2018.

[75] C. E. Brown, B. Aguilar, R. Starr et al., "Optimization of IL13R $\alpha 2$-targeted chimeric antigen receptor $T$ cells for improved anti-tumor efficacy against glioblastoma," Molecular Therapy, vol. 26, no. 1, pp. 31-44, 2018.

[76] L. Shen, H. Li, S. Bin et al., "The efficacy of third generation anti-HER2 chimeric antigen receptor T cells in combination with PD1 blockade against malignant glioblastoma cells," Oncology Reports, vol. 42, no. 4, pp. 1549-1557, 2019.

[77] A. Sahin, C. Sanchez, S. Bullain, P. Waterman, R. Weissleder, and B. S. Carter, "Development of third generation antiEGFRvIII chimeric T cells and EGFRvIII-expressing artificial antigen presenting cells for adoptive cell therapy for glioma," PLoS One, vol. 13, no. 7, article e0199414, 2018.

[78] H. Zhu, Y. You, Z. Shen, and L. Shi, "EGFRvIII-CAR-T cells with PD-1 knockout have improved anti-glioma activity," Pathology Oncology Research, vol. 26, no. 4, pp. 2135-2141, 2020.

[79] K. Bielamowicz, K. Fousek, T. T. Byrd et al., “Trivalent CAR $\mathrm{T}$ cells overcome interpatient antigenic variability in glioblastoma," Neuro-Oncology, vol. 20, no. 4, pp. 506-518, 2018.

[80] W. Wick and R. J. Wagener, "Not yet another negative trialReACTing on recent glioblastoma trials," Clinical Cancer Research, vol. 26, no. 7, pp. 1535-1537, 2020.

[81] D. A. Reardon, A. Desjardins, J. J. Vredenburgh et al., "Rindopepimut with bevacizumab for patients with relapsed EGFRvIII-expressing glioblastoma (ReACT): results of a double-blind randomized phase II trial," Clinical Cancer Research, vol. 26, no. 7, pp. 1586-1594, 2020.

[82] S. Phuphanich, C. J. Wheeler, J. D. Rudnick et al., "Phase I trial of a multi-epitope-pulsed dendritic cell vaccine for patients with newly diagnosed glioblastoma," Cancer Immunology, Immunotherapy, vol. 62, no. 1, pp. 125-135, 2013. 
[83] P. Y. Wen, D. A. Reardon, T. S. Armstrong et al., “A randomized double-blind placebo-controlled phase II trial of dendritic cell vaccine ICT-107 in newly diagnosed patients with glioblastoma," Clinical Cancer Research, vol. 25, no. 19, pp. 5799-5807, 2019.

[84] M. W. Kieran, L. Goumnerova, P. Manley et al., "Phase I study of gene-mediated cytotoxic immunotherapy with AdV-tk as adjuvant to surgery and radiation for pediatric malignant glioma and recurrent ependymoma," NeuroOncology, vol. 21, no. 4, pp. 537-546, 2019.

[85] L. A. Wheeler, A. G. Manzanera, S. D. Bell et al., "Phase II multicenter study of gene-mediated cytotoxic immunotherapy as adjuvant to surgical resection for newly diagnosed malignant glioma," Neuro-Oncology, vol. 18, no. 8, pp. 1137-1145, 2016.

[86] E. G. Chavez-Cortez, G. Vargas Felix, E. Rangel López et al., "Production and evaluation of an avian IgY immunotoxin against CD133+ for treatment of carcinogenic stem cells in malignant glioma: IgY immunotoxin for the treatment of glioblastoma," Journal of Oncology, vol. 2019, Article ID 2563092, 15 pages, 2019.

[87] C. C. Hu, H. M. Ji, S. L. Chen et al., "Investigation of a plasmid containing a novel immunotoxin VEGF165-PE38 gene for antiangiogenic therapy in a malignant glioma model," International Journal of Cancer, vol. 127, no. 9, pp. 22222229,2010

[88] X. Bao, I. Pastan, D. D. Bigner, and V. Chandramohan, "EGFR/EGFRvIII-targeted immunotoxin therapy for the treatment of glioblastomas via convection-enhanced delivery," Receptors \& clinical investigation, vol. 3, no. 4, 2016.

[89] V. Chandramohan, X. Bao, X. Yu et al., "Improved efficacy against malignant brain tumors with EGFRwt/EGFRvIII targeting immunotoxin and checkpoint inhibitor combinations," Journal for immunotherapy of cancer, vol. 7, no. 1, p. 142, 2019.

[90] V. Chandramohan, X. Bao, S. T. Keir et al., "Construction of an immunotoxin, D2C7-(scdsFv)-PE38KDEL, targeting EGFRwt and EGFRvIII for brain tumor therapy," Clinical Cancer Research, vol. 19, no. 17, pp. 4717-4727, 2013.

[91] J. M. Chemnitz, R. V. Parry, K. E. Nichols, C. H. June, and J. L. Riley, "SHP-1 and SHP-2 associate with immunoreceptor tyrosine-based switch motif of programmed death 1 upon primary human T cell stimulation, but only receptor ligation prevents T cell activation," Journal of Immunology, vol. 173, no. 2, pp. 945-954, 2004.

[92] J. X. Guo, C. X. Wu, P. F. Wang et al., "Bioactivity and safety of chimeric switch receptor T cells in glioblastoma patients," Front Biosci (Landmark Ed), vol. 24, no. 6, pp. 1158-1166, 2019.

[93] J. Loya, C. Zhang, E. Cox, A. S. Achrol, and S. Kesari, “Biological intratumoral therapy for the high-grade glioma part I: intratumoral delivery and immunotoxins," CNS oncology, vol. 8, no. 3, p. CNS38, 2019.

[94] M. Candolfi, K. Kroeger, W. Xiong et al., “Targeted toxins for glioblastoma multiforme: pre-clinical studies and clinical implementation," Anti-Cancer Agents in Medicinal Chemistry, vol. 11, no. 8, pp. 729-738, 2011.

[95] G. Liu, X. Yuan, Z. Zeng et al., "Analysis of gene expression and chemoresistance of CD133+ cancer stem cells in glioblastoma," Molecular Cancer, vol. 5, no. 1, p. 67, 2006.

[96] P. J. Wookey, C. A. McLean, P. Hwang et al., "The expression of calcitonin receptor detected in malignant cells of the brain tumour glioblastoma multiforme and functional properties in the cell line A172," Histopathology, vol. 60, no. 6, pp. 895910, 2012.

[97] R. Gilabert-Oriol, S. G. B. Furness, B. W. Stringer et al., "Dianthin-30 or gelonin versus monomethyl auristatin E, each configured with an anti-calcitonin receptor antibody, are differentially potent in vitro in high-grade glioma cell lines derived from glioblastoma," Cancer Immunology, Immunotherapy, vol. 66, no. 9, article 2013, pp. 1217-1228, 2017.

[98] Y. Ke, Y. Zhang, X. Sun, M. Huang, J. Wang, and X. Liu, “A novel bispecific immunotoxin delivered by human bone marrow-derived mesenchymal stem cells to target blood vessels and vasculogenic mimicry of malignant gliomas," Drug Design, Development and Therapy, vol. 9, pp. 2947-2959, 2015.

[99] J. Schuster, R. K. Lai, L. D. Recht et al., "A phase II, multicenter trial of rindopepimut (CDX-110) in newly diagnosed glioblastoma: the ACT III study," Neuro-Oncology, vol. 17, no. 6, pp. 854-861, 2015.

[100] M. Weller, N. Butowski, D. D. Tran et al., "Rindopepimut with temozolomide for patients with newly diagnosed, EGFRvIII- expressing glioblastoma (ACT IV): a randomised, double-blind, international phase 3 trial," The Lancet Oncology, vol. 18, no. 10, pp. 1373-1385, 2017.

[101] A. M. Swartz, Q. J. Li, and J. H. Sampson, "Rindopepimut: a promising immunotherapeutic for the treatment of glioblastoma multiforme," Immunotherapy, vol. 6, no. 6, pp. 679690, 2014.

[102] B. Pineda, F. J. Sánchez García, N. K. Olascoaga et al., "Malignant glioma therapy by vaccination with irradiated C6 cellderived microvesicles promotes an antitumoral immune response," Molecular Therapy, vol. 27, no. 9, pp. 1612-1620, 2019.

[103] B. D. Lichty, C. J. Breitbach, D. F. Stojdl, and J. C. Bell, "Going viral with cancer immunotherapy," Nature Reviews. Cancer, vol. 14, no. 8, pp. 559-567, 2014.

[104] Q. A. Alayo, H. Ito, C. Passaro et al., "Glioblastoma infiltration of both tumor- and virus-antigen specific cytotoxic $\mathrm{T}$ cells correlates with experimental virotherapy responses," Scientific reports, vol. 10, no. 1, p. 5095, 2020.

[105] Z. Zhu, M. J. Gorman, L. D. McKenzie et al., "Zika virus has oncolytic activity against glioblastoma stem cells," The Journal of Experimental Medicine, vol. 214, no. 10, pp. 28432857, 2017.

[106] A. F. Haddad, J. S. Young, N. V. Mummaneni, N. Kasahara, and M. K. Aghi, "Immunologic aspects of viral therapy for glioblastoma and implications for interactions with immunotherapies," Journal of Neuro-Oncology, vol. 152, no. 1, pp. 113, 2021.

[107] J. Hardcastle, L. Mills, C. S. Malo et al., "Immunovirotherapy with measles virus strains in combination with anti-PD-1 antibody blockade enhances antitumor activity in glioblastoma treatment," Neuro-Oncology, vol. 19, no. 4, pp. 493502, 2017.

[108] S. Rajaraman, D. Canjuga, M. Ghosh et al., "Measles virusbased treatments trigger a pro-inflammatory cascade and a distinctive immunopeptidome in glioblastoma," Molecular Therapy-Oncolytics, vol. 12, pp. 147-161, 2019.

[109] J. Kiyokawa and H. Wakimoto, "Preclinical and clinical development of oncolytic adenovirus for the treatment of malignant glioma," Oncolytic virotherapy, vol. 8, pp. 27-37, 2019 . 
[110] F. Alessandrini, L. Menotti, E. Avitabile et al., "Eradication of glioblastoma by immuno-virotherapy with a retargeted oncolytic HSV in a preclinical model," Oncogene, vol. 38 , no. 23, pp. 4467-4479, 2019.

[111] Z. Zhu, P. Mesci, J. A. Bernatchez et al., "Zika virus targets glioblastoma stem cells through a SOX2-integrin $\alpha_{\mathrm{v}} \beta_{5}$ axis," Cell Stem Cell, vol. 26, no. 2, pp. 187-204.e10, 2020.

[112] Q. Chen, J. Wu, Q. Ye et al., “Treatment of human glioblastoma with a live attenuated zika virus vaccine candidate," mBio, vol. 9, no. 5, 2018.

[113] S. Nair, L. Mazzoccoli, A. Jash et al., "Zika virus oncolytic activity requires CD8+ $\mathrm{T}$ cells and is boosted by immune checkpoint blockade," JCI Insight, vol. 6, no. 1, 2021.

[114] K. Geletneky, J. Hajda, A. L. Angelova et al., "Oncolytic H-1 parvovirus shows safety and signs of immunogenic activity in a first phase I/IIa glioblastoma trial," Molecular Therapy, vol. 25, no. 12, pp. 2620-2634, 2017.

[115] S. Adams, C. Teo, K. L. McDonald et al., "Involvement of the kynurenine pathway in human glioma pathophysiology," PLoS One, vol. 9, no. 11, article e112945, 2014.

[116] J. D. Mezrich, J. H. Fechner, X. Zhang, B. P. Johnson, W. J. Burlingham, and C. A. Bradfield, "An interaction between kynurenine and the aryl hydrocarbon receptor can generate regulatory T cells," Journal of Immunology, vol. 185, no. 6 , pp. 3190-3198, 2010.

[117] P. Terness, T. M. Bauer, L. Röse et al., "Inhibition of allogeneic $\mathrm{T}$ cell proliferation by indoleamine 2,3-dioxygenaseexpressing dendritic cells: mediation of suppression by tryptophan metabolites," The Journal of Experimental Medicine, vol. 196, no. 4, pp. 447-457, 2002.

[118] S. Adams, N. Braidy, A. Bessesde et al., "The kynurenine pathway in brain tumor pathogenesis," Cancer Research, vol. 72, no. 22, pp. 5649-5657, 2012.

[119] M. Li, A. R. Bolduc, M. N. Hoda et al., “The indoleamine 2,3dioxygenase pathway controls complement-dependent enhancement of chemo-radiation therapy against murine glioblastoma," Journal for Immunotherapy of Cancer, vol. 2, no. 1, p. 21, 2014.

[120] M. Hanihara, T. Kawataki, K. Oh-Oka, K. Mitsuka, A. Nakao, and H. Kinouchi, "Synergistic antitumor effect with indoleamine 2,3-dioxygenase inhibition and temozolomide in a murine glioma model," Journal of Neurosurgery, vol. 124, no. 6, pp. 1594-1601, 2016.

[121] L. Zhai, K. L. Lauing, A. L. Chang et al., "The role of IDO in brain tumor immunotherapy," Journal of Neuro-Oncology, vol. 123, no. 3, pp. 395-403, 2015.

[122] C. Riess, B. Schneider, H. Kehnscherper et al., "Activation of the kynurenine pathway in human malignancies can be suppressed by the cyclin-dependent kinase inhibitor dinaciclib," Frontiers in Immunology, vol. 11, p. 55, 2020.

[123] G. Frumento, R. Rotondo, M. Tonetti, G. Damonte, U. Benatti, and G. B. Ferrara, "Tryptophan-derived catabolites are responsible for inhibition of $\mathrm{T}$ and natural killer cell proliferation induced by indoleamine 2,3-dioxygenase," The Journal of Experimental Medicine, vol. 196, no. 4, pp. 459468, 2002.

[124] B. Campos, L. R. Olsen, T. Urup, and H. S. Poulsen, "A comprehensive profile of recurrent glioblastoma," Oncogene, vol. 35, no. 45, pp. 5819-5825, 2016.

[125] M. Buglione, S. Pedretti, P. L. Poliani et al., "Pattern of relapse of glioblastoma multiforme treated with radical radio-che- motherapy: could a margin reduction be proposed?," Journal of Neuro-Oncology, vol. 128, no. 2, pp. 303-312, 2016.

[126] E. Vlashi, C. Lagadec, L. Vergnes et al., "Metabolic state of glioma stem cells and nontumorigenic cells," Proceedings of the National Academy of Sciences of the United States of America, vol. 108, no. 38, pp. 16062-16067, 2011.

[127] F. Ye, Y. Zhang, Y. Liu et al., "Protective properties of radiochemoresistant glioblastoma stem cell clones are associated with metabolic adaptation to reduced glucose dependence," PLoS One, vol. 8, no. 11, article e80397, 2013.

[128] I. Saga, S. Shibao, J. Okubo et al., "Integrated analysis identifies different metabolic signatures for tumor-initiating cells in a murine glioblastoma model," Neuro-Oncology, vol. 16, no. 8, pp. 1048-1056, 2014.

[129] S. Shibao, N. Minami, N. Koike et al., "Metabolic heterogeneity and plasticity of glioma stem cells in a mouse glioblastoma model," Neuro-Oncology, vol. 20, no. 3, pp. 343-354, 2018.

[130] S. H. Soomro, L. R. Ting, Y. Y. Qing, and M. Ren, "Molecular biology of glioblastoma: classification and mutational locations," The Journal of the Pakistan Medical Association, vol. 67, no. 9, pp. 1410-1414, 2017.

[131] S. Negrini, V. G. Gorgoulis, and T. D. Halazonetis, "Genomic instability - an evolving hallmark of cancer," Nature Reviews. Molecular Cell Biology, vol. 11, no. 3, pp. 220-228, 2010.

[132] T. N. Schumacher and R. D. Schreiber, "Neoantigens in cancer immunotherapy," Science, vol. 348 , no. 6230 , pp. 69-74, 2015.

[133] Z. Hu, P. A. Ott, and C. J. Wu, “Towards personalized, tumour-specific, therapeutic vaccines for cancer," Nature Reviews. Immunology, vol. 18, no. 3, pp. 168-182, 2018. 